\title{
Isotope Dilution Gas Chromatography/Mass Spectrometry for Platinum Determination in Urine
}

\author{
Suresh K. Aggarwal, Michael Kinter, and David A. Herold \\ University of Virginia Health Sciences Center, Department of Pathology, Charlottesville, Virginia, USA
}

\begin{abstract}
The therapeutic importance of platinum (Pt) compounds, the growing accessibility of gas chromatography/mass spectrometry (GC/MS) systems in clinical laboratories, and the lack of a mass spectrometric method for the determination of $\mathrm{Pt}$ in biological samples motivated us to develop an isotope dilution GC/MS assay for Pt. The method is based on the use of lithium bis(trifluoroethyl)dithiocarbamate, Li(FDEDTC), as a chelating agent and enriched ${ }^{192} \mathrm{Pt}$ for isotope dilution. Conditions were optimized for the precise and accurate determination of isotope ratios of Pt by using a 10-m DB- 1 fused silica capillary column and a reverse-geometry double-focusing mass spectrometer with selected ion monitoring. An overall precision of $1 \%$ was obtained by combining within-run precision and between-run precision at the 10-ng level. No appreciable memory effect was observed when samples with different isotope ratios were analyzed sequentially. The method was validated by the quantitation of Pt in National Institute of Standards and Technology freeze-dried urine sample SRM 2670. A concentration value of $125 \pm 6 \mu \mathrm{g} / \mathrm{L}(n=6)$ was obtained by using four different sets of isotope ratios in the molecular ion and supports the National Institute of Standards and Technology recommended value of $120 \pm ? \mu \mathrm{g} / \mathrm{L}$. Limits-of-quantitation, estimated at $3 \mu \mathrm{g} / \mathrm{L}$, are made possible by the high sensitivity of the method and the low blank value for Pt. (J Am Soc Mass Spectrom 1991, 2, 85-90)
\end{abstract}

$\mathrm{P}$ latinum $(\mathrm{Pt})$ compounds are important antineoplastic drugs. Because urine concentrations of these drugs are closely related to the non-protein-bound drug concentration in the blood [1], measurement of urine Pt concentration offers an excellent, noninvasive way to monitor drug levels. Many of the analytical methods used for determining $\mathrm{Pt}$ in biological samples are either too insensitive or too plagued by other problems like matrix effects to be of value for this measurement. The obvious advantages of isotope dilution are freedom from matrix effects and results that are not dependent on the quantitative recovery of the analyte.

In our laboratory we have been pursuing gas chromatography/mass spectrometry (GC/MS) determination of trace metals in biological samples [2-4]. The main factors that appear to have precluded the widespread use and acceptability of GC/MS for metals determination are (1) lack of suitable chelating agents, (2) memory problem leading to cross-contamination in the sequential analyses of samples with different isotope ratios, and (3) poor precision and accuracy in isotope ratio measurements. Isotope dilution GC/MS (IDGC/MS) methods have been reported

Address reprint requests to David A. Herold, University of Virginia Health Sciences Center, Department of Pathology, Box 168, Charlottesville, VA 22908. by others for the determination of $\mathrm{Cr}$ [5-7] and Se [8, 9]. We have reported the development of IDGC/MS methods for the determination of $\mathrm{Ni}$ [3] and $\mathrm{Cr}$ [4] in urine samples. This study reports the extension of our techniques to the determination of isotope ratios and concentration of $\mathrm{Pt}$ in urine samples. Memory effects were studied by sequential analyses of samples with different isotope ratios. Precision and accuracy in isotope ratio measurements were established by replicate determinations of the natural $\mathrm{Pt}$ on different days. Finally, the IDGC/MS method for determining Pt concentration was validated by analysis of National Institute of Standards and Technology (NIST) urine reference material.

\section{Experimental}

\section{Instrumentation}

The mass spectrometer used was a double-focusing reverse-geometry instrument (Model 8230, Finnigan MAT, San Jose, CA) with a SpectroSystem 300 data system. The instrument was operated in the electron ionization (EI) mode using $70-\mathrm{eV}$ electrons with a source temperature of $200^{\circ} \mathrm{C}$, the conversion dynode at $-5000 \mathrm{~V}$, and the secondary electron multiplier at $2000 \mathrm{~V}$. The focusing conditions of the mass spectrometer were optimized and the mass calibration was 
established by injecting perfluorokerosene into the reference inlet. The fragmentation pattern of the metal chelate was recorded by employing the exponential scarning mode ( $1 \mathrm{~s}$ per decade) and adjusting the source and the collector slits to obtain a triangular peak shape. Isotope ratios were measured in the selected ion monitoring mode using voltage peak switching. The source and the collector slits were adjusted to obtain trapezoidal peaks with flat tops (collector slit width > source slit width) and the data were acquired at $2 \mathrm{~Hz}$, yielding approximately 20 data points across the 10-s wide GC peak. A mass resolution of $\mathbf{1 0 0 0}$ was used throughout. The isotope ratios were calculated by integrating the ion current for various chromatographic peaks rather than by taking the peak heights. The overall linearity of the mass spectrometer was checked by injecting methyl stearate into the GC column and measuring the isotope ratios with $m / z$ values of $299 / 298,300 / 298,301 / 298$, and $302 / 298$; these ratius differed by four urders of magnitude. Other details of the measurement methodology were published earlier [2].

A Varian 3700 gas chromatograph equipped with a DB-1 (J. W. Scientific, Rancho Cordova, CA) poly(dimethylsiloxane) bonded-phase fused silica capillary column, $10 \mathrm{~m} \times 0.32 \mathrm{~mm}$, with a $0.25-\mu \mathrm{m}$ film thickness was used. Platinum chelate samples were injected by using an on-column injector (OCI-3, Scientific Glass Engineering, Austin, TX) at an oven temperature of $100^{\circ} \mathrm{C}$ followed by a $25^{\circ} \mathrm{C} / \mathrm{min}$ temperature ramp to $300{ }^{\circ} \mathrm{C}$. High-purity helium was used as a carrier gas.

\section{Reagents}

The ${ }^{192} \mathrm{Pt}$ (50 atom\%) used as a spike for isotope dilution was obtained from Oak Ridge National Laboratory (Oak Ridge, TN). Certified Atomic Absorption Standard ( $\mathrm{Pt}$ in 10\% $\mathrm{HCl}$ ) purchased from Spex Industrics Inc. (Edison, NJ) was used as the primary standard for spike calibration. Double subboiling quartz-distilled $\mathrm{HNO}_{3}$ in Teflon bottles was obtained from the NIST (Gaithersburg, MD). Ultrex grade $\mathrm{NH}_{4} \mathrm{OH}$ solution $(30 \%), \mathrm{HCl}(12 \mathrm{~N})$, and ortho- $\mathrm{H}_{3} \mathrm{PO}_{4}$ $(86 \%)$ were obtained from J. T. Baker Chemical $\mathrm{Co}$. (Phillipsburg, NJ). Formic acid $(90 \%)$ and stabilized hydrogen peroxide (50\%) were obtained from Fisher Scientific (Fairlawn, NJ). The standard reference material, freeze-dried urine SRM 2670, was also purchased from the NIST and prepared according to their directions. Lithium bis(trifluoroethyl)dithiocarbamate, Li(FDEDTC), was synthesized by reacting bis(trifluoroethyl)amine (PCR Inc., Gainesville, FL) and nbutyl-lithium (Aldrich Chemical Co., Milwaukee, WI) in an inert atmosphere at $-70^{\circ} \mathrm{C}$ followed by the addition of carbon disulfide (Aldrich) $[2,10]$.

Contamination control, always important in trace metals analysis, would not be considered a major problem when working with $\mathrm{Pt}$ because of the rarity of this element. Nonetheless, normal trace metals procedures to avoid contamination were followed, e.g., use of acid-leached Polypropylene/Teflon labware, deionized water (DW), powder-free gloves, and a clean hood with laminar flow.

\section{Preparation and Standardization of Spike Solution}

The ${ }^{142} \mathrm{Pt}$ spike solution was prepared by dissolving the metal in a minimum amount of aqua regia at 70 ${ }^{\circ} \mathrm{C}$. This solution was then taken to the appropriate volume with dilute $\mathrm{HCl}$. More dilute spike solutions were prepared from this stock solution on a weight basis for isotope dilution experiments. The isotopic composition of $\mathrm{Pt}$ in the spike was determined experimentally by GC/MS analysis of Pt(FDEDTC) ${ }_{2}$ chelate. The spike solution was calibrated as previously reported by reverse-isotope dilution GC/MS using the natural $\mathrm{Pt}$ primary standard $[3,4]$.

\section{Digestion of Urine Samples and Chelate Formation}

A known volume $(0.5 \mathrm{~mL})$ of the reconstituted urine reference material was mixed with a weighed amount of ${ }^{192} \mathrm{Pt}$ spike solution in a Teflon beaker. The spiked mixture was treated with $2.5 \mathrm{~mL}$ of concentrated $\mathrm{HNO}_{3}$ and $0.5 \mathrm{~mL}$ of concentrated $\mathrm{H}_{3} \mathrm{PO}_{4}(5: 1, \mathrm{v} / \mathrm{v})$ and allowed to stand overnight to partially digest the organic matter and reduce foaming during subsequent heating. The partially digested solution was then heated gently on a hot plate at $70{ }^{\circ} \mathrm{C}$ to reduce the volume, and $1 \mathrm{~mL}$ of $50 \% \mathrm{H}_{2} \mathrm{O}_{2}$ solution was slowly added to the hot solution until no visible brown fumes of nitrogen dioxide were released. Subsequently, $0.5 \mathrm{~mL}$ of formic acid was added to destroy the residual $\mathrm{HNO}_{3}$ [11]. The solution was evaporated to $0.5 \mathrm{~mL}$, and $0.5 \mathrm{~mL}$ of $10 \% \mathrm{HCl}$ was added. The volume of the solution was taken to $5 \mathrm{~mL}$ with $\mathrm{DW}$ and extracted with $2 \mathrm{~mL}$ of $\mathrm{CH}_{2} \mathrm{Cl}_{2}$, discarding the organic phase to remove any undigested lipids. The $\mathrm{pH}$ of the aqueous phase was adjusted to $2-3$ by using about $200 \mu \mathrm{L}$ of concentrated $\mathrm{NH}_{3}$ solution; 1 $\mathrm{mL}$ of $\mathrm{pH} 3$ acetate buffer was added and the $\mathrm{Pt}$ chelate formed by adding $200 \mu \mathrm{L}$ of a $20-\mathrm{mM}$ solution of the chelating agent $\mathrm{Li}$ (FDEDTC). The $\mathrm{Pt}$ chelate was extracted with two $500-\mu \mathrm{L}$ aliquots of $\mathrm{CH}_{2} \mathrm{Cl}_{2}$. The organic extract containing the $\mathrm{Pt}$ chelate was allowed to evaporate to dryness at room temperature in the laminar flow hood and reconstituted in $20 \mu \mathrm{L}$ of $\mathrm{CH}_{2} \mathrm{Cl}_{2}$ for analysis.

\section{Gas Chromatography/Mass Spectrometry}

The $\mathrm{Pt}$ isotope ratios were measured in duplicate by injecting $1 \mu \mathrm{L}$ of the chelate solution and monitoring the cluster of peaks corresponding to the molecular ion. Because the measurements were performed without using a lock mass, it was necessary to determine the $m / z$ value of the peak maximum experimentally 


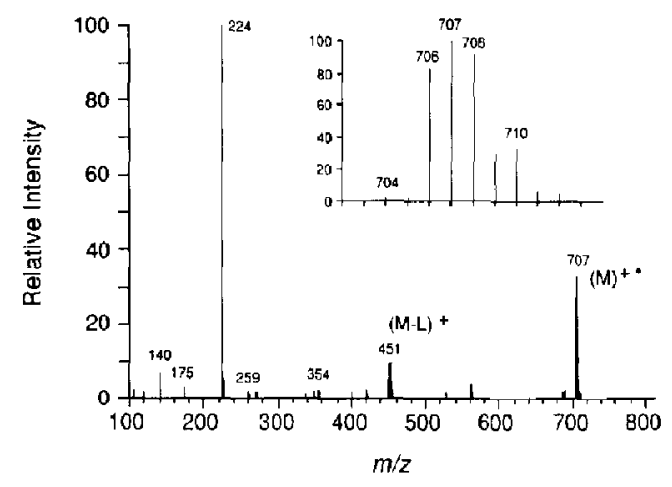

Figure 1. Electron ionization mass spectrum of 1 t $(\text { FLELVIC })_{2}$ (the sample contained $10 \mathrm{ng}$ of $\mathrm{Pt}$ ).

by obtaining a histogram of the ion current adjacent to and including the calculated $\mathrm{m} / \mathrm{z}$ value of a given ion. Details of the methodology were published earlier [2]. Concentrations of $\mathrm{Pt}$ were then calculated by the usual method of isotope dilution [12].

\section{Results and Discussion}

The EI mass spectrum of Pt(FDEDTC) $)_{2}$, shown in Figure 1, exhibits two groups of ions containing $\mathrm{Pt}$ isotopic information. These ions are the molecular ion Pt(FDEDTC) ${ }_{2}^{+*}$ and a fragment ion Pt(FDEDTC) ${ }^{+}$, designated by $\mathrm{M}^{+\cdot}$ and $[\mathrm{M}-\mathrm{L}]^{+}$, respectively. The ion at $m / z 224$, corresponding to $\left(\mathrm{CF}_{3} \mathrm{CH}_{2}\right)_{2} \mathrm{NCS}^{+}$, is the base peak but is not useful for Pt analysis. The most abundant isotopic group, the $\mathrm{M}^{+}$. ion, was used throughout these experiments to achieve highest possible sensitivity. This ion group consists of nominal $m / z$ values of $702,704,706,707,708$, and 710 , corresponding respectively to ${ }^{190} \mathrm{Pt},{ }^{192} \mathrm{Pt},{ }^{194} \mathrm{Pt},{ }^{195} \mathrm{Pt},{ }^{196} \mathrm{Pt}$ and ${ }^{198} \mathrm{Pt}$ isotopes. Further, the presence of the molecular ion as well as the observation of symmetrical and sharp chromatographic peaks indicated the adequate thermal stability and volatility of the $\mathrm{Pt}$ chelate at nanogram levels under the conditions used in these experiments.
Tables 1 and 2 show the results obtained for isotope ratio measurements of natural $\mathrm{Pt}$ and enriched ${ }^{192} \mathrm{Pt}$, respectively. For these measurements, $1 \mu \mathrm{L}$ of the chelate solution containing about $10 \mathrm{ng}$ of $\mathrm{Pt}$ was used for analysis. The atom percent abundances shown in Table 1 for the different isotopes in natural $P t$ are the recommended values based on the values measured experimentally by different laboratories [13]. The atom percent abundances shown in Table 2 for the different $\mathrm{Pt}$ isotopes in enriched ${ }^{192} \mathrm{Pt}$ are the values provided by the Oak Ridge National Laboratory. The calculated values for the abundances of the molecular ion of the chelate, also given in Tables 1 and 2, were obtained by calculating the contributions of the isotopes of $\mathrm{Pt}$, carbon, nitrogen, and sulfur in the molecular ion [14, 15]. As shown in Tables 1 and 2 , there is good agreement between the calculated and measured abundances of the molecular ion in natural $\mathrm{Pt}$ and in the ${ }^{192} \mathrm{Pt}$ spike. No correction has been applied to the experimental data shown in Tables 1 and 2 for any mass discrimination among the different isotopes. Moreover, any mass discrimination factor would be canceled in isotope dilution experiments because the spike calibration is also done in the same experiment.

Precision in the determination of various isotope ratios was evaluated by performing measurements of chelated natural Pt on four different days. Three to six replicate analyses of $10 \mathrm{ng}$ of $\mathrm{Pt}$ were made on each of the four days and the data are summarized in Table 3. The mean values for each day were used to calculate the mean of means and its standard deviation, referred to as between-run precision in Table 3 . The within-run precision was obtained by considering the standard deviation values obtained on the individual days. Overall precision was calculated by combining the within-run and between-run precision values to evaluate the effects of any variations in the mass spectrometer operating parameters that may affect the isotope ratio data from one day to another. No significant difference was observed among the isotope ratios measured on different days. Overall precision values of approximately $1 \%$ were obtained for all the isotope ratios except the $m / z 704 / 707$ ratio, which

lable 1. Calculated and measured abundances of different ions in natural Pt(FDEDTC $)_{2}$

\begin{tabular}{|c|c|c|c|c|}
\hline \multirow[b]{2}{*}{ Isotope } & \multirow[b]{2}{*}{$\begin{array}{c}\text { Atom\% } \\
\text { abundance }\end{array}$} & \multicolumn{3}{|c|}{ Molecular ion $\left(\mathrm{M}^{+\cdot}\right)$} \\
\hline & & $\begin{array}{c}\operatorname{lon} \\
(m / z)\end{array}$ & $\begin{array}{c}\text { Calculated } \\
\text { abundance } \\
(\%)\end{array}$ & $\begin{array}{c}\text { Measured } \\
\text { abundance } \\
(\%)\end{array}$ \\
\hline${ }^{190} \mathrm{Pt}$ & 0.01 & 702 & 0.01 & $b$ \\
\hline${ }^{192} \mathrm{Pt}$ & 0.79 & 704 & 0.65 & 0.76 \\
\hline${ }^{194} \mathrm{Pt}$ & 32.90 & 706 & 26.95 & 26.85 \\
\hline${ }^{195} \mathrm{Pt}$ & 33.80 & 707 & 31.67 & 31.07 \\
\hline${ }^{196} \mathrm{Pt}$ & 25.30 & 708 & 29.90 & 29.43 \\
\hline${ }^{198} \mathrm{Pt}$ & 7.20 & 710 & 10.84 & 11.89 \\
\hline
\end{tabular}

Including the contributions of the isotopes of $\mathrm{Pt}$, carbon, nitrogen, and sulfur in the ion PtifDEDTC) ${ }_{2}^{+}$.

b Intensity below detection limits. 
Table 2. Calculated and measured abundances of different ions in ${ }^{192} \mathrm{Pt}(\mathrm{FDEDTC})_{2}$

\begin{tabular}{ccccc}
\hline & & \multicolumn{3}{c}{ Molecular ion $\left(\mathrm{M}^{+}\right)$} \\
\cline { 3 - 5 } $\begin{array}{c}\text { Atom\% } \\
\text { Isotope }\end{array}$ & $\begin{array}{c}\text { Ion } \\
\text { abundance }\end{array}$ & $\begin{array}{c}\text { Calculated } \\
\text { abundance } \\
(\mathrm{m} / \mathrm{z})\end{array}$ & $\begin{array}{c}\text { Measured } \\
(\%)\end{array}$ & $\begin{array}{c}\text { abundance } \\
(\%)\end{array}$ \\
\hline \hline${ }^{190} \mathrm{Pt}$ & $<0.05$ & 702 & $<0.04$ & 0.09 \\
${ }^{192} \mathrm{Pt}$ & 50.03 & 704 & 40.20 & 37.84 \\
${ }^{194} \mathrm{Pt}$ & 24.25 & 706 & 27.06 & 26.74 \\
${ }^{195} \mathrm{Pt}$ & 16.23 & 707 & 17.05 & 17.72 \\
${ }^{196} \mathrm{Pt}$ & 8.00 & 708 & 12.63 & 13.70 \\
${ }^{198} \mathrm{Pt}$ & 1.49 & 710 & 3.01 & 3.90 \\
\hline
\end{tabular}

\footnotetext{
${ }^{a}$ Values given by Oak Ridge National Laboratory.

bincluding the contributions of the isotopes of $\mathrm{Pt}$, carbon, nitrogen, and sulfur in the ion
} Pt(FDEDTC) ${ }_{2}^{+\cdot}$.

gave a precision of $5 \%$ due to the low natural abundance of ${ }^{192} \mathrm{Pt}$.

\section{Evaluation of the Memory Effect}

Memory effect refers to cross-contamination in the GC/MS system during the sequential analyses of samples with different isotope ratios. This cross-contamination can adversely affect the accuracy of the measurement of altered isotope ratios. In these studies, the memory effect was evaluated in two different ways.

The first approach used to investigate the memory effect was an evaluation of the accuracy of determining isotope ratios different from those of natural $\mathrm{Pt}$. For this experiment, three synthetic mixtures differing in the $m / z 704 / 707$ ratio by a factor of about 16 (range $0.05-0.81$ ) were prepared by mixing weighed aliquots of the primary standard solution and the enriched ${ }^{192} \mathrm{Pt}$ solution in differing proportions but containing almost equal amounts of total Pt. This was done to observe the extent of memory in samples that are most commonly encountered in isotope dilution experiments. Three analyses, each with $10 \mathrm{ng}$ of $\mathrm{Pt}$, were made for each mixture, and the isotope ratios $m / z$ 704/706, 704/707, and 704/708 were determined. The mixtures were analyzed in the sequence of increasing isotope ratios and then in the reverse sequence. Figure 2 shows the $\mathrm{m} / \mathrm{z} 704 / 707$ isotope ratios determined in these mixtures. Only a slight memory effect is observed in analysis number 13, which immediately followed samples with dramatjcally different isotope ratios.

The second approach involved the sequential analyses of a solution of natural $\mathrm{Pt}$ and a solution of enriched ${ }^{192} \mathrm{Pt}$. The ratio $m / z 704 / 707$ was measured because it corresponds to the maximum abundant isotopes, ${ }^{192} \mathrm{Pt}$ in the spike and ${ }^{195} \mathrm{Pt}$ in the natural $\mathrm{Pt}$. The analyses were carried out in the following sequence: five injections of natural $\mathrm{Pt}$, five injections of ${ }^{192} \mathrm{Pt}$ spike, followed by seven injections of natural $\mathrm{Pt}$. The results are presented in Figure 3. Again, only a slight memory effect is observed in analysis number 11 , which immediately followed samples with isotope ratios differing by a factor of about 80 . Hence a small memory effect is seen for only the first new sample after a large change in ratio. The slight extent of memory effects is not a problem.

Table 3. Precision of isotope ratio determination of natural $\mathrm{Pt}$ as $\mathrm{Pt}(\text { FDEDTC })_{2}$

\begin{tabular}{|c|c|c|c|c|}
\hline & \multicolumn{4}{|c|}{ Isotope ratio ${ }^{a}$ (mean \pm rsd) } \\
\hline & $704 / 707$ & $706 / 707$ & $708 / 707$ & $710 / 707$ \\
\hline Day $1(n=6)$ & $0.0256 \pm 3.2 \%$ & $0.8593 \pm 1.1 \%$ & $0.9488 \pm 0.4 \%$ & $0.3849 \pm 1.2 \%$ \\
\hline Day $2(n=6)$ & $0.0250 \pm 3.9 \%$ & $0.8677 \pm 0.7 \%$ & $0.9422 \pm 0.7 \%$ & $0.3790 \pm 2.3 \%$ \\
\hline Day $3(n)=5)$ & $0.0250 \pm 6.5 \%$ & $0.8620 \pm 0.9 \%$ & $0.9489 \pm 0.8 \%$ & $0.3832 \pm 1.2 \%$ \\
\hline Day $4(n=3)$ & $0.0230 \pm 3.3 \%$ & $0.8677 \pm 0.1 \%$ & $0.9483 \pm 0.5 \%$ & $0.3832 \pm 1.2 \%$ \\
\hline Mean of means & 0.0246 & 0.8642 & 0.9471 & 0.3826 \\
\hline Within-run precision, ${ }^{b} \%$ & 2.2 & 0.4 & 0.3 & 0.8 \\
\hline Between-run precision, \% & 4.6 & 0.5 & 0.3 & 0.7 \\
\hline Overall precision, ${ }^{c} \%$ & 5.1 & 0.6 & 0.4 & 1.1 \\
\hline
\end{tabular}




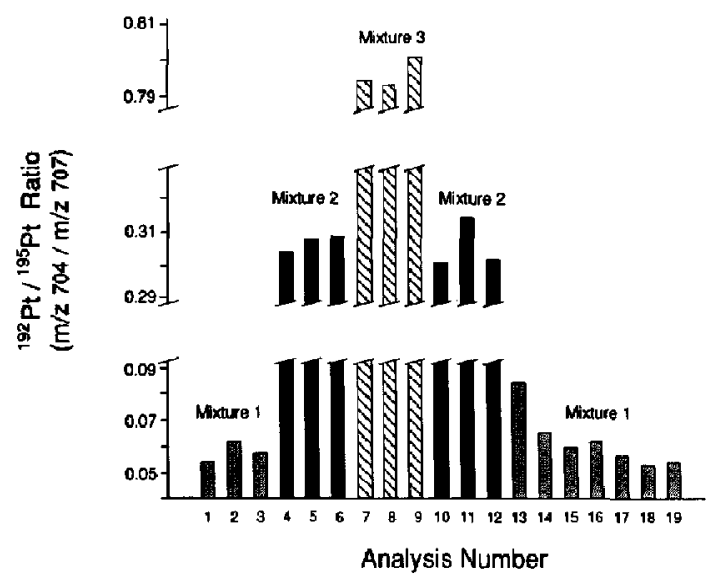

Figure 2. Evaluation of cross-contamination in consecutive analyses of samples with slightly altered isotopic composition.

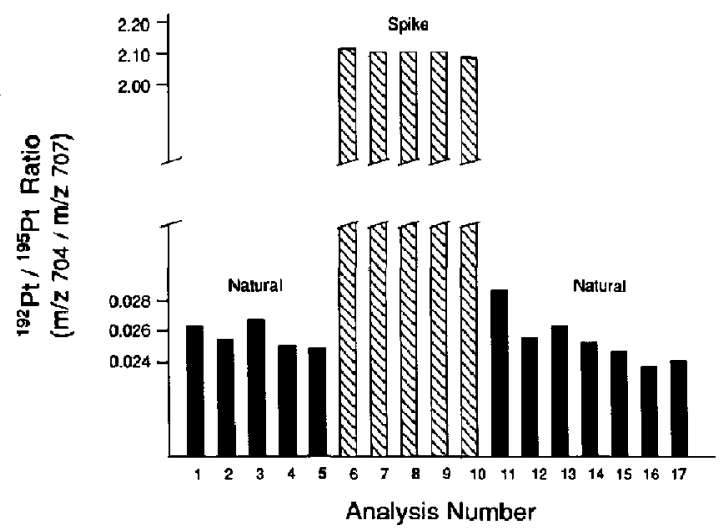

Figure 3. Evaluation of cross-contamination of samples with isotopic composition differing by a factor of 80 . Analyses 1-5 and 11-17 are of a natural Pt sample and analyses 6-10 are of enriched ${ }^{192} \mathrm{Pt}$ sample.

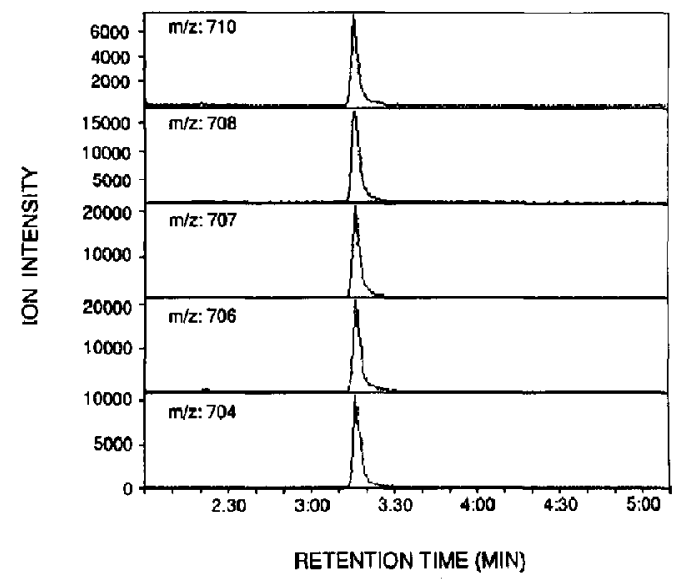

Figure 4. Reconstructed ion chromatogram for the determination of $\mathrm{Pt}$ in the urine sample SRM 2670 (the sample injected contained $10 \mathrm{ng}$ of $\mathrm{Pt}$ ).

\section{Calibration of ${ }^{192}$ Pt Spike Solution}

The ${ }^{192} \mathrm{Pt}$ spike solution was calibrated by reverse-isotope dilution using a primary standard of natural $\mathrm{Pt}$. For this standardization, five samples were prepared by mixing weighed aliquots of primary standard and ${ }^{192} \mathrm{Pt}$ spike solutions to achieve an optimum isotope ratio $m / z 704 / 707$ in the spiked mixtures. The results obtained for Pt concentration in the spike solution are given in Table 4. The values calculated from the different isotope ratios are all in good agreement. The relative standard deviations observed for these concentration values are smaller than those from synthetic mixtures because the optimum sample-to-spike ratio was measured during the reverse-isotope dilution experiment for spike calibration, whereas the synthetic mixtures comprised a range of isotope ratios.

\section{Results on Urine Samples}

The calibrated ${ }^{192} \mathrm{Pt}$ spike solution was used to quantify $\mathrm{Pt}$ in the NIST freeze-dried urine reference material SRM 2670. A high signal-to-noise ratio, shown in

Table 4. Determination of $\mathrm{Pt}$ in ${ }^{192} \mathrm{Pt}$ spike solution by reverse-isotope dilution GC/MS

\begin{tabular}{|c|c|c|c|}
\hline \multirow[b]{3}{*}{ Ratio } & \multicolumn{3}{|c|}{ Concentration of $\mathrm{Pt}(\mu \mathrm{g}$ of $\mathrm{Pt} / \mathrm{g}$ of solution $)$} \\
\hline & \multirow[b]{2}{*}{$\begin{array}{l}\text { Optimum spiking } \\
\text { (mean } \pm \text { rsd })^{\mathrm{b}}\end{array}$} & \multicolumn{2}{|c|}{ Synthetic mixtures ${ }^{a}$} \\
\hline & & $\stackrel{A}{(m e a n \pm r s d\}^{c}}$ & $\frac{B}{(\text { mean } \pm r s d)^{c}}$ \\
\hline $704 / 706$ & $49.09 \pm 1.2 \%$ & $49.74 \pm 2.7 \%$ & $50.86 \pm 3.1 \%$ \\
\hline $704 / 707$ & $48.29 \pm 1.4 \%$ & $48.81 \pm 3.6 \%$ & $49.69 \pm 4.4 \%$ \\
\hline $704 / 708$ & $47.86 \pm 1.0 \%$ & $48.65 \pm 3.4 \%$ & $49.06 \pm 4.3 \%$ \\
\hline $704 / 710$ & $47.85 \pm 0.9 \%$ & - & - \\
\hline
\end{tabular}

${ }_{A} A$ and $B$ represent the sequence of GC/MS analyses of synthetic mixtures; $A$ denotes the analysis sequence with increasing isotope ratio and $B$ denotes the analysis sequence in the reverse order.

$n=5$.
$n=3$ 
Table 5. Determination of $\mathrm{Pt}$ in urine (SRM 2670)

\begin{tabular}{ccccc}
\hline & \multicolumn{4}{c}{ Concentration of $\mathrm{Pt}(\mu \mathrm{g} / \mathrm{L})$ using various ion ratios } \\
\cline { 2 - 5 } Semple no. & $704 / 706$ & $704 / 707$ & $704 / 708$ & $704 / 710$ \\
\hline 1 & 127 & 126 & 123 & 117 \\
2 & 122 & 126 & 123 & 114 \\
3 & 126 & 126 & 117 & 109 \\
4 & 131 & 125 & 129 & 114 \\
5 & 136 & 129 & 133 & 124 \\
6 & 132 & 131 & 134 & 121 \\
\hline Mean \pm rsd & $129 \pm 5$ & $127 \pm 2$ & $127 \pm 7$ & $117 \pm 5$ \\
\hline
\end{tabular}

the reconstructed ion chromatogram in Figure 4, indicates potential limits of detection below the parts per billion level. Limits-of-quantitation are estimated to be better than $3 \mu \mathrm{g} / \mathrm{L}$. The results obtained for Pt concentration in the urine sample SRM 2670 are shown in Table 5. Since the recommended Pt concentration values in the urine are provided in the units of $\mu \mathrm{g} / \mathrm{L}$ by NIST, the urine samples were taken on a volume basis instead of a weight basis. The concentration values calculated by using the different isotope ratios are in very good agreement with one another. The value of $125 \pm 6 \mu \mathrm{g} / \mathrm{L}$ calculated from these data supports the revised (April 12, 1989, NIST Certificate of Analysis) recommended value of $120 \mu \mathrm{g} / \mathrm{L}$ for $\mathrm{Pt}$ rather than the earlier (December 3, 1985) recommended value of $110 \mu \mathrm{g} / \mathrm{L}$. It should be noted that the NIST recommended value does not have the standard deviation provided.

\section{Conclusions}

Stable IDGC/MS using Li(FDEDTC) as a chelating agent is a sensitive method for $\mathrm{Pt}$ determination in urine. There is no appreciable memory effect and the method gives good precision and accuracy for $\mathrm{Pt}$ isotope ratio measurements.

\section{Acknowledgments}

Funding for the purchase of the high-resolution mass spectrometer was obtained from the National Institutes of Health, Division of Research Resources Shared Instrumentation Grant Program, grant no. 1-S10-RRO-2418-01. Additional funding from the John Lee Pratt Fund of the University of Virginia is gratefully acknowledged. S. K. A. thanks the Division of Experimental Pathology, Department of Pathology, University of Virginia
Health Sciences Center, for a post-doctoral fellowship, and the authorities at Bhabha Atomic Research Center, Trombay, Bombay-400 085, India, for granting leave from July 1987 to July 1989 and deputation from June 1990 to August 1990. The authors thank Patrick K. Anonick for assistance in the synthesis of the chelating agent and J. Savory and M. R. Wills for their interest in the present work and for allowing use of the facilities available in the trace metals laboratory.

\section{References}

1. Walker, E. M., Jr.; Gale, G. R. Amer. Assoc. for Clin. Chem. $1990,11,7-17$.

2. Aggarwal, S. K.; Kinter, M.; Wills, M. R.; Savory, J.; Herold, D. A. Anal. Chim. Acta 1989, 224, 83-95.

3. Aggarwal, S. K.; Kinter, M.; Wills, M. R.; Savory, J.; Herold, D. A. Anal. Chem. 1989, 61, 1099-1103.

4. Aggarwal, S. K.; Kinter, M.; Wills, M. R.; Savory, J.; Herold, D. A. Anal. Chem. 1990, 62, 111-115.

5. Frew, N. M.; Leary, J. J.; Isenhour, T. L. Anal. Chem. 1972, 44, 665-671.

6. Veillon, C.; Wolf, W. R.; Guthrie, B. E. Anal. Chem. 1979, 51, 1022-1024.

7. Siu, K. W. M.; Bednas, M. E.; Berman, S. S. Anal. Chem. 1983, 55, 473-476.

8. Reamer, D. C.; Veillon, C. Aral. Chem. 1981, 53, 2166-2169.

9. Reamer, D. C.; Veillon, C. J. Nutr. 1983, 713, 786-792.

10. Sucre, L.; Jennings, W. Anal. Lett. 1980, 13, 497-501.

11. Lewis, S. A. In Methods in Enzymology, Vol. 158, Part A; Riordan, J. F.; Vallee, B. L., Eds.; Academic: San Diego, 1988; Chapter 31.

12. Aggarwal, S, K,; Duggal, R. K.; Rao, R.; Jain, H. C. Int. J. Mass Spectrom. Ion Processes 1986, 71, 221-231.

13. DeBievre, P.; Gallet, M.; Holden, N. E.; Barnes, I. L. J. Phys. Chem. Ref. Data 1984, 13, 809-891.

14. Beynon, I. II. Mass Spectromelry ard Its Applicutiuns to Organic Chemistry; Elsevier: Amsterdam, 1960.

15. Beynon, J. H.; Williams, A. E. Mass and Abundance Tables for Use in Mass Spectrometry; Elsevier: Amsterdam, 1963. 